\title{
O desenvolvimento de games como metodologia de ensino-aprendizagem e estratégia para promover o protagonismo juvenil
}

\author{
Ana Paula Cavadas Rodrigues ${ }^{3}$, Raquel Moreira Machado Fernandes ${ }^{1,2}$, Leniah Lima \\ Teixeira ${ }^{3}$, Claudia Lage Rebello da Motta ${ }^{1,3}$, Carla Verônica Machado Marques ${ }^{3}$, Carlo \\ Emmanoel Tolla de Oliveira ${ }^{3}$
${ }^{1}$ Programa de Pós Graduação em Informática da Universidade Federal do Rio de Janeiro
${ }^{2}$ Universidade Federal Fluminense Federal do Rio de Janeiro \\ ${ }^{3}$ Instituto Tércio Pacitti de Aplicações e Pesquisas Computacionais da Universidade
}

anapcavadas@gmail.com,raquelmachado@id.uff.br,claudiam@nce.ufrj.br, leniahlima@gmail.com,carlo@nce.ufrj.br, carlaveronica@nce.ufrj.br

\begin{abstract}
This article presents an experience of using a neuropedagogical strategy for the development of intelligent games as a learning tool, aiming to promote the cognitive and social development of areas of great social vulnerability through the use of Digital Information and Communication Technologies. Students, by appropriating technology, become multipliers of the processes they experience, spreading computational thinking and metacognition.
\end{abstract}

Resumo. Este artigo tem como objetivo apresentar a experiência de utilização de uma estratégia neuropedagógica para o desenvolvimento de games inteligentes como instrumento de aprendizagem, visando promover o desenvolvimento cognitivo e o resgate de estudantes que vivem em áreas de grande vulnerabilidade social através da utilização das Tecnologias Digitais de Informação e Comunicação (TDIC). Os estudantes, ao apropriarem-se da tecnologia, tornam-se multiplicadores dos processos que vivenciaram, difundindo o pensamento computacional e a metacognição.

\section{Informações gerais}

Esta pesquisa de caráter qualitativo inicia-se com a constatação da necessidade de acessibilidade aos avanços tecnológicos na Educação em áreas de vulnerabilidade social, tendo como referência a região denominada Complexo da Pedreira, situada em Costa Barros, mas que também engloba os bairros de Acari, Barros Filho, Coelho Neto e Pavuna. Estes, ocupam posições inferiores no ranking de índice de desenvolvimento humano da cidade do Rio de Janeiro. Segundo dados mais recentes do Instituto Brasileiro de Geografia e Estatística, Costa Barros foi o $125^{\circ}$ colocado entre 126 regiões analisadas no município do Rio de Janeiro, superando apenas o Complexo do Alemão.

Acreditou-se, portanto, na tecnologia como uma possibilidade em busca do desenvolvimento integral dos estudantes desta região, numa proposta de educação holística capaz de estimular o desenvolvimento dos indivíduos em prol de uma sociedade pautada em ideais de respeito, igualdade e integridade. 
VIII Congresso Brasileiro de Informática na Educação (CBIE 2019)

Anais do XXX Simpósio Brasileiro de Informática na Educação (SBIE 2019)

Desse modo, apresenta-se neste artigo um método metacognitivo para projeto e desenvolvimento de gamificação para apoiar os processos de ensino-aprendizagem e promover o protagonismo juvenil.

\section{Fundamentação Teórica}

Esta pesquisa baseia-se fortemente nas pesquisas de Franco Lo Presti Seminério, que investigou a aprendizagem e o desenvolvimento cognitivo de crianças em contextos de vulnerabilidade social e fundamenta-se em conceitos interdisciplinares, oriundos principalmente das áreas de Neurociência, Pedagogia e Computação. Entre os principais conceitos presentes na investigação, cita-se a metacognição e o pensamento computacional.

A metacognição é o exercício de tomada de consciência das regras de um conhecimento, que estão ligadas a níveis diferentes de consciência. O momento em que ocorre a tomada de consciência dessas regras pode ser otimizado porque a metacognição é um recurso que pode ser manipulado de forma intencional [Marques, 2017].

De acordo com Wing [2006], o pensamento computacional é um meio para a resolução de problemas de forma criativa utilizando os conceitos da Ciência da Computação.

Tais conceitos fundamentam uma proposta de educação holística que integre o estudante na construção consciente de seu próprio conhecimento.

\section{Trabalhos relacionados}

Com o intuito de utilizar a tecnologia e os jogos digitais para impulsionar a cognição e a aprendizagem, as pesquisas de Marques [2015, 2017] apresentam-nos o conceito de game inteligente, pelo qual pode-se aliar a Neurociência e a Tecnologia em prol da Educação.

Os trabalhos: O Jogo da Trilha Topológica: Proposta de Convalidação na versão virtual [Barreira et al., 2014], Fases de Construção de um Jogo Virtual para Mensurar a Inovação e a Heurística. [Pimentel et al., 2014], e Modelo fractal das Microgêneses Cognitivas: Uma Metodologia para a Mediação Metacognitiva em Jogos Computacionais [Lemos et al., 2012] revelam indícios de que a utilização de games inteligentes gera resultados positivos.

A grande inovação desta pesquisa foi o desenvolvimento de um método para projeto e desenvolvimento de gamificação baseado em um modelo mental de aprendizagem, cuja a natureza é de ordem não determinística. Deste modo, esta pesquisa diferencia-se das demais por utilizar conceitos advindos da Informática, como o Pensamento Computacional, dentro de um currículo rizomático com a aplicação de técnicas neurocientíficas, como o Fio Condutor Pedagógico Metacognitivo [Rodrigues, 2018], transformando uma metodologia complexa em algo aprazível para estudantes dos ensinos médio e fundamental, contribuindo para o empoderamento de meninas e meninos quanto à mudança de perspectiva de vida, causando um impacto de grande valia para toda a sociedade.

\section{Objetivos}

A pesquisa objetivou promover o resgate de estudantes que vivem em uma área de grande vulnerabilidade social através de um método para projeto e desenvolvimento de gamificação para apoiar os processos de ensino-aprendizagem, que constitui-se das seguintes etapas: 
VIII Congresso Brasileiro de Informática na Educação (CBIE 2019)

Anais do XXX Simpósio Brasileiro de Informática na Educação (SBIE 2019)

1. Letramento digital com a utilização de Tecnologias Digitais de Informação e Comunicação (TDIC);

2. Abordagem neuropedagógica para o desenvolvimento da cognição e da metacognição dos alunos envolvidos;

3. Ensino da metodologia de concepção de games inteligentes [Marques, 2015; 2017] e ensino da linguagem de programação com atividades práticas;

4. Multiplicação do conhecimento adquirido através da atividade de construção colaborativa de um game.

A elaboração dessas etapas fundamentou-se nos pressupostos teóricos mencionados na seção 2, considerando contribuições dos trabalhos mencionados na seção 3 e são passíveis de serem replicadas em diferentes contextos educacionais com abordagem teórica e empírica.

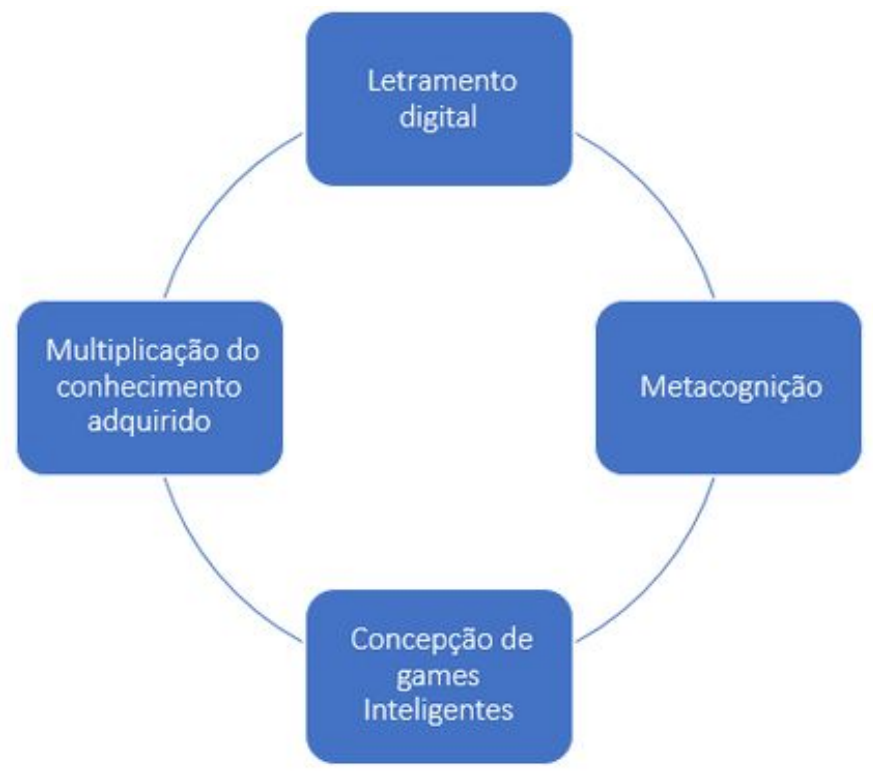

Figura 1. Etapas do modelo apresentado

O modelo representado na Figura 1 é um processo não direcional que reflete a priorização de um ensino adaptativo e evolutivo que leve o estudante ao desenvolvimento de sua cognição, preservando a sua individualidade e sabendo que a adaptação exerce uma importante participação no processo de aprendizagem. Desse modo, privilegiou-se sistemas acentrados, redes de autômatos finitos e estados caóides [Gallo, 1995] para a elaboração de uma estrutura na qual o planejamento é uma ideia discutida amplamente no cotidiano. Dessa forma, o planejamento foi feito e refeito por várias vezes, discutindo-se e considerando-se a participação dos estudantes.

\section{Metodologia}

Para a condução da pesquisa, utilizou-se a metodologia de pesquisa-ação, mais próxima da modalidade pesquisa-ação-política segundo a definição de Filippo et al. [2018].

Durante todo o processo, utilizou-se metodologias neurocognitivas como o Fio Condutor Pedagógico Metacognitivo proposto por Rodrigues [2018]. Nesta metodologia, o estudante é ensinado a resolver problemas em grupo, verbalizar as 
VIII Congresso Brasileiro de Informática na Educação (CBIE 2019)

Anais do XXX Simpósio Brasileiro de Informática na Educação (SBIE 2019)

soluções e aprender a aprender através de diferentes linguagens, mídias e suportes, em atividades distribuídas em etapas.

$\mathrm{Na}$ etapa 1, foram realizadas atividades lúdicas, atividades de iniciação à Informática e atividades de Computação desplugada, de modo a desenvolver o imaginário e o pensamento computacional. A programação e o pensamento computacional foram abordados de forma transversal no currículo, através de estratégias de composição e decomposição de problemas, abstração, paralelismo, simulação, coleta, análise e representação de dados.

$\mathrm{Na}$ etapa 2, utilizou-se a linguagem Python para promover a prática, adaptando-se o processo de desenvolvimento de games inteligentes segundo Marques [2015] para transformá-lo em um modelo neuropedagógico capaz de possibilitar ao estudante um desenvolvimento cognitivo e um protagonismo capaz de não apenas torná-lo ativo na construção de seu próprio conhecimento, mas ativo também em sua comunidade local. O caráter científico do processo de construção deste tipo de jogo garante a sua eficácia como instrumento de medida e intervenção.

$\mathrm{Na}$ etapa 3, após três meses de formação, os estudantes do ensino médio tornaram-se monitores dos estudantes do ensino fundamental, trabalhando com duas turmas do segundo segmento, que possuem estudantes de idade entre doze e quinze anos. A primeira turma era mista, composta por vinte alunos de ambos os sexos e o foco do trabalho foi a concepção e o desenvolvimento de games a partir da criação de jogos analógicos; a segunda turma era composta de quinze meninas e o foco do trabalho foi o empoderamento feminino através da criação de games.

As atividades aplicadas aos estudantes do ensino fundamental foram discutidas, analisadas e deliberadas colaborativamente pelos estudantes do ensino médio, e foram realizadas na sala de projetos da escola, tendo cada encontro a duração aproximada de 3 horas. A Figura 2 contém um registro das interações.

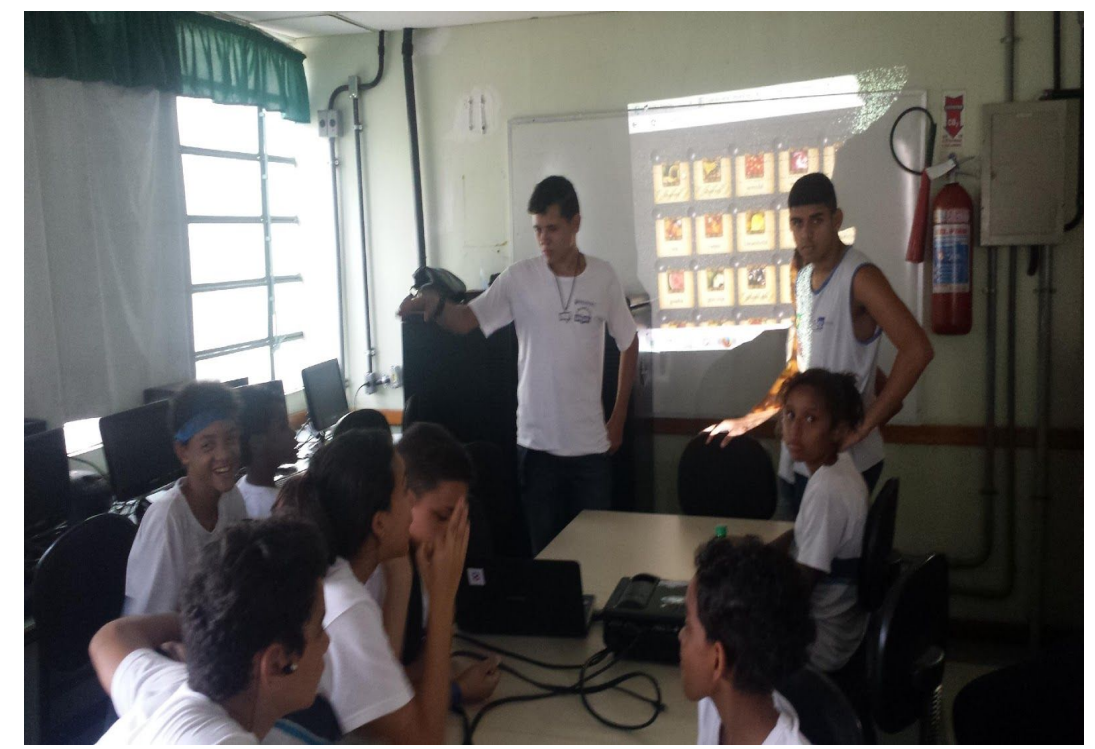

Figura 2. Estudantes planejando ações de forma colaborativa

\section{O game inteligente}

Segundo Rodrigues [2018], denomina-se game inteligente um jogo baseado em princípios neurocientíficos que através da construção do pensamento computacional e da investigação científica auxilia o estudante a "aprender a aprender" . 
VIII Congresso Brasileiro de Informática na Educação (CBIE 2019)

Anais do XXX Simpósio Brasileiro de Informática na Educação (SBIE 2019)

Segundo Marques [2015], a elaboração de um game inteligente envolve quatro grandes processos: modelagem dimensional, processo criativo, projeto interacional e desenvolvimento conceitual. Esta pesquisa apresenta um método em que esses processos podem ser utilizados numa perspectiva neuropedagógica, de forma que professores da educação básica podem apropriar-se para otimizar o processo de aprendizagem e difundir a tecnologia através dos games.

O game inteligente busca construir através da orientação do professor mediador, a criação do conhecimento individual de cada aluno. Para tanto, histórias são criadas a partir do conhecimento prévio dos alunos sobre o tema abordado. Nesta pesquisa, selecionou-se o estudo de genética e da afetividade, e os alunos envolveram-se na tarefa de criar um game inteligente a partir desta temática.

Para o início das atividades, os alunos realizaram uma pesquisa de caráter bibliográfico e utilizaram a plataforma https://activufrj.nce.ufrj.br/bookmarks/Kwarwp, onde foram colocados diversos textos, páginas e artigos, a fim de que pudessem aprofundar o estudo sobre os temas e criar suas próprias histórias.

Esta pesquisa bibliográfica originou o processo de modelagem dimensional, em que foram selecionadas três dimensões: a genética, a Taxonomia de Bloom, que avalia o conhecimento do jogador a respeito da genética, e a afetividade, que busca levar esse conhecimento para a vida dos alunos, despertando o autoconhecimento.

Segundo Ferraz [2010] a Taxonomia de Bloom é um instrumento de avaliação da dimensão cognitiva, nesse caso a genética. Está relacionada ao aprender, dominar um conhecimento. Envolve seis categorias e são apresentados numa hierarquia de complexidade e dependência, do mais simples ao mais complexo, representadas em seis verbos: Lembrar, entender, aplicar, analisar, avaliar e criar.

A dimensão afetividade refere-se à capacidade do ser humano de ser afetado pelo mundo externo e interno, por sensações agradáveis ou desagradáveis. [De Almeida, 2010] A autora ainda descreve quatro momentos marcantes e sucessivos na evolução humana: sensibilidade, emoção, sentimento e paixão. No caso desse jogo, o recorte realizado privilegiou apenas a sensibilidade na forma da visão ou audição, o que pode ser agradável ou desagradável em ver ou ouvir para o jogador.

As atividades realizadas oportunizaram a criação de um game de Genética, parte da biologia que se refere ao estudo da transmissão das características hereditárias ao longo das gerações. No game, a cientista Rosalinda Franco redescobre um segredo guardado por sua tia avó Rosalind Franklin. No entanto, ela desaparece misteriosamente. Em sua casa vazia um livro de anotações chama atenção por ter diversas páginas faltando. Na primeira página ela pede para encontrar páginas de um livro de genética, que ajudará a elucidar o caso.

Desse modo, mediou-se as atividades para que o game pudesse possibilitar, durante a jogada, a criação de um livro com lições de genética. Os alunos puderam, através do pensamento computacional, elaborar os desafios pertinentes à temática inserindo-os no jogo sob a forma de main quests e side quests, como forma de ampliar os conhecimentos do jogador. A missão principal, que é possibilitar, no jogo, a construção do livro, foi criada e materializada pelos alunos de forma colaborativa.

A Tabela 1 apresenta um exemplo de instrução utilizada para estimular o imaginário dos alunos de modo que conseguissem criar as questões do game. 
VIII Congresso Brasileiro de Informática na Educação (CBIE 2019)

Anais do XXX Simpósio Brasileiro de Informática na Educação (SBIE 2019)

Tabela 1. Instrução de mediação para criação de questões no game inteligente

DIMENSÕES: Sensibilidade, DNA, lembrar

PROPOSTA: Crie uma história em que o jogador necessite lembrar a constituição do DNA para continuar a jogada; nessa história, a sensação auditiva ou sonora pode ajudá-lo em uma situação de perigo, por exemplo.

Os main quest e side quests são compostos de itens de genética mais aprofundados em que temos uma espinha dorsal com várias perguntas realizadas, cujas respostas levam ao conhecimento aprofundado do tema principal.

Os códigos desenvolvidos pelos alunos para a criação do game foram disponibilizados no repositório digital Github e podem ser consultados no endereço: https://github.com/kwarwp/dame.

\section{O Fio Condutor Pedagógico Metacognitivo}

No intuito de recrutar funções executivas, durante as aulas de games, foi apresentado um problema no qual o estudante era estimulado a buscar a solução. Tal problema é denominado Objeto Real do Conhecimento (ORC) [Marques, 2009]

Para esta pesquisa, foram feitas inovações na técnica do Fio Condutor Técnico, descrito inicialmente por Marques [2009], para se adequar aos materiais disponibilizados nas escolas da Prefeitura do Rio de Janeiro, no segundo segmento do Ensino Fundamental. O novo Fio condutor Pedagógico Metacognitivo apresenta cinco fases, representadas na Figura 3:

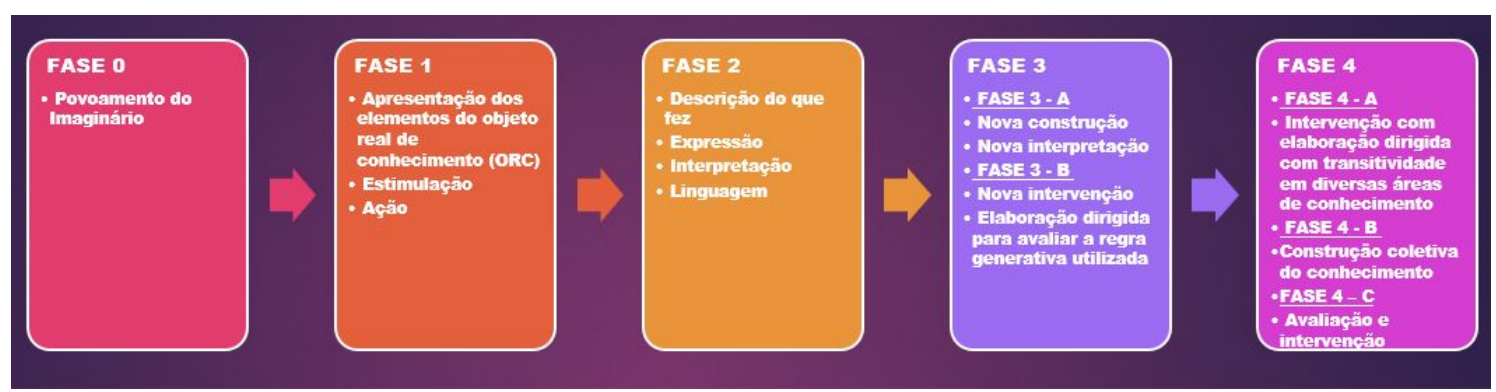

Figura 3. Fases do Fio Condutor Pedagógico Metacognitivo segundo Rodrigues [2018]

No Fio Condutor Pedagógico Metacognitivo também foram utilizados conceitos sobre Grupo Operativo de Enrique Pichon Rivière, psiquiatra e psicanalista suíço nacionalizado argentino, que designa grupo operativo como o constituído de pessoas reunidas com o objetivo comum, chamado de grupo centrado na tarefa. Tal grupo tem por objetivo aprender a pensar em termos de resolução das dificuldades criadas e manifestadas no campo grupal. Nesse grupo, cada membro tem um papel específico a ser atribuído, porém podendo assumir outros papéis funcionais durante o processo; esses papéis podem ser assumidos previamente ou não. No caso desta pesquisa, os papéis 
VIII Congresso Brasileiro de Informática na Educação (CBIE 2019)

Anais do XXX Simpósio Brasileiro de Informática na Educação (SBIE 2019)

foram assumidos antecipadamente, pois os líderes do grupo seriam os estudantes que haviam chegado ao conhecimento do ORC de forma satisfatória.

$\mathrm{Na}$ abordagem pedagógica da criação de sistemas, explora-se a transdisciplinaridade intrínseca do processo e adapta-se a sequência de atividades a um processo de aperfeiçoamento cognitivo.

A divisão de papéis é uma característica importante para uma ativação cognitiva de diversas funções executivas. A rotação do estudante entre estes papéis melhora a capacidade de atenção, transição de contexto e controle inibitório. [Rodrigues, 2018]

\section{Resultados}

A realização desta pesquisa promoveu um avanço na lógica e na proatividade dos estudantes envolvidos. No geral, todos demonstraram melhor desempenho nas matérias e em suas vidas escolares. A escola passou a ter uma função social e o ensino passou a ter uma dinâmica mais divertida, eficaz e descontraída.

Desse modo, trabalhando com conceitos advindos da Informática com o Pensamento Computacional dentro de um currículo rizomático com a aplicação de técnicas neurocientíficas, foi possível transformar uma metodologia complexa em algo aprazível para estudantes do ensino fundamental e médio.

Destaca-se também como resultado e contribuição da pesquisa o empoderamento de meninas e meninos quanto à mudança de perspectiva de vida, o que traz um impacto benéfico para toda a sociedade.

Em relação ao modelo de aula desenvolvido, aplicou-se um survey para saber qual modelo de aula era mais prazeroso e em qual modelo eles achavam que aprendiam mais o conteúdo: naquela aula em que o professor colocava a matéria no quadro e eles copiavam e realizavam atividades, ou naquela em que eles eram estimulados a resolver problemas, como as aulas de laboratório, ou as de informática. Todos foram unânimes em responder que preferiam o segundo modelo de aula.

Outro fator importante a ser relatado como resultado é o fato de que estudantes avaliados como insuficientes nas aulas expositivas tradicionais, desempenharam atividades de programação e experimentos de maneira satisfatória; daí a grande importância da diversificação das atividades escolares e a importância de se repensar os processos de avaliação escolar.

Outro resultado positivo do desenvolvimento desta pesquisa foi a diminuição do número de faltas nos dias da execução do projeto.

Vale ressaltar que os alunos do ensino médio que participaram dessa pesquisa foram apresentar esse trabalho no Python Sudeste-2019, um evento da comunidade de programadores e entusiastas da linguagem Python que aconteceu em Vitória no Espírito Santo e foram convidados a participar da próxima edição do evento Python Brasil.

Também houve o convite para a chamada MCTIC/CNPq N $\mathrm{N}^{\circ} 05 / 2019$ PROGRAMA CIÊNCIA NA ESCOLA, pelo Instituto Nacional de Tecnologia. Desta forma, realizou-se uma parceria entre o Laboratório de Automação de Sistemas de Engenharia da Universidade Federal do Rio de Janeiro, a Escola Municipal Jornalista e Escritor Daniel Piza e o Colégio Estadual Marechal Zenóbio da Costa, onde as atividades foram realizadas. Os resultados positivos contribuíram para a continuidade do projeto e desse modo, espera-se ampliar a formação para cada vez mais estudantes. 
VIII Congresso Brasileiro de Informática na Educação (CBIE 2019)

Anais do XXX Simpósio Brasileiro de Informática na Educação (SBIE 2019)

\section{Considerações finais e perspectivas futuras}

Através desta pesquisa, buscou-se promover a ampliação do conhecimento científico ao apresentar um caso em que se demonstra que metodologias neurocientífico-pedagógicas como o Fio Condutor Pedagógico Metacognitivo descrito em Rodrigues [2018], com o auxílio da Informática, podem ser utilizadas como estratégia neuropedagógica por professores da educação básica, constituindo-se um método para desenvolver e promover a gamificação não apenas como forma de ludificar a aprendizagem, mas sim como processo de aprendizagem, através do qual os estudantes desenvolvem a metacognição e podem aprofundar os estudos de uma determinada temática. Por meio da ação empírica, promoveu-se uma melhoria em um problema real que ocorre no ambiente particular em que a pesquisa foi realizada, onde a criação do jogo pelos próprios estudantes se transformou em um estímulo interno, gerando um sentimento de auto-eficácia, descrito por Bandura [1977]. Os discentes sentiram-se competentes por construírem algo, na perspectiva do construcionismo incitada por Papert [1994] e através do estímulo metacognitivo e do uso das ferramentas computacionais, tornaram-se autores de uma nova trajetória de aprendizagem e atuação social.

Sugere-se como trabalhos futuros a realização de estudos quantitativos para medição da aprendizagem, de modo que seja possível ter dados concretos a respeito da qualidade da aprendizagem obtida com a utilização deste método.

Sugere-se também a continuidade da utilização da tecnologia como forma de promover o protagonismo juvenil, investigando-se também novas metodologias, abordagens e a construção de outros tipos de artefatos computacionais, bem como a ampliação da atuação do trabalho dos alunos multiplicadores para abranger mais escolas.

\section{Referências}

Almeida, Ana Rita Silva (2001). O que é afetividade? Reflexões para um conceito. Anais da XXIV Reunião Anual da ANPEd.

Bandura, Albert; Azzi, Roberta G.; Polydoro, Soely Aparecida. (2009) Teoria social cognitiva: conceitos básicos. Porto Alegre: Artmed, p.15-41.

Bandura, A. (1977). Social Learning Theory. Englewood Cliffs, N.J: Prentice-Hall.

Barreira, Christiana V.; Marques, Carla Verônica M.; Oliveira, Carlo E. T.; Motta, Cláudia L. R. (2012) Jogo da Trilha Topológica: Um Game Inteligente em Ação. Anais do $23^{\circ}$ Simpósio Brasileiro de Informática na Educação.

Bezerra, Ricardo José Lima. (2012) Afetividade como condição para a aprendizagem: Henri Wallon e o desenvolvimento cognitivo da criança a partir da emoção. Revista Didática Sistêmica 4 (2010): 20-26.

Dantas Vanessa F., et al. (2013) Combinando desafios e aventura em um jogo para apoiar a aprendizagem de programação em vários níveis cognitivos. Brazilian Symposium on Computers in Education (Simpósio Brasileiro de Informática na

Educação-SBIE). v.24, n.1. 
VIII Congresso Brasileiro de Informática na Educação (CBIE 2019)

Anais do XXX Simpósio Brasileiro de Informática na Educação (SBIE 2019)

De Almeida, Nilma Figueredo, \& Franco Lo Presti Seminério. (2010) Cognição e Emoção: a importância do imaginário para a metacognição e a educação. Disponível em

$<\mathrm{http}: / / w w w . u f r r j . b r /$ leptrans/arquivos/Arquivo_06_COGNIcAO_E_EMOcAO_A_i mp.pdf $>$ Acesso em 30 ago 2019

Ferraz, A. P. C. M. and Renato Vairo Belhot. (2010) Taxonomia de Bloom: revisão teórica e apresentação das adequações do instrumento para definição de objetivos instrucionais. Gest. Prod., São Carlos. p 421-431.

Filippo, D.; Roque, G.; Pedrosa, S. (2018) "Pesquisa-ação: possibilidades para a Informática Educativa." in Metodologia de Pesquisa Científica em Informática na Educação: Abordagem qualitativa de Pesquisa. Volume 3. Comissão Especial de Informática na Educação, Sociedade Brasileira de Computação.

Gallo, Sílvio. (1995) Conhecimento, transversalidade e currículo. Trabalho apresentado na $21^{\text {a }}$ Reunião Anual da ANPEd. Programa e resumos, p. 135. Associação Nacional de Pós-graduação e Pesquisa em Educação (ANPEd).

Instituto Brasileiro de Geografia e Estatística. Tabela 1172 - Índice de Desenvolvimento Humano Municipal (IDH), por ordem de IDH, segundo os bairros ou grupo de bairros - $2000 . \quad$ Disponível em $<$ http://www.camara.rj.gov.br/planodiretor/pd2009/saudepd/Anexo3_IDH.pdf> Acesso em 30 ago 2019

Lemos, Myriam K. (2012). Modelo fractal das microgêneses cognitivas: uma metodologia para a mediação metacognitiva em jogos computacionais. Anais do 23 Simpósio Brasileiro de Informática na Educação (SBIE 2012) ISSN 2316-6533. Rio de Janeiro.

Marques, Carla V. M. et al. (2009) A revolução cognitiva; um estudo sobre a teoria de Franco Lo Presti Seminério. Rio de Janeiro. PPGI/IM/NCE,(2009b). (Relatório Técnico, 04/09).

Marques, Carla V. M. et al. (2015) Game inteligente: conceito e aplicação. Anais do Seminário de Jogos Eletrônicos, Educação e Comunicação, v. 1, n. 1.

Marques, Carla V. M. (2017) "Eica - Estruturas Internas Cognitivas Aprendentes: Um Modelo Neuro-Computacional Aplicado À Instância Psíquica Do Sistema Pessoa Em Espaços Dimensionais”. Universidade Federal do Rio de Janeiro.

Papert, Seymour M. (1994). A Máquina das Crianças: Repensando a Escola na Era da Informática. Porto Alegre, Artes Médicas, 210 pp.

Pimentel, Ana P. C. (2014) Fases de Construção de um Jogo Virtual para Mensurar a Inovação e a Heurística. Nuevas Ideas en Informatica Educativa TISE 2014 
VIII Congresso Brasileiro de Informática na Educação (CBIE 2019)

Anais do XXX Simpósio Brasileiro de Informática na Educação (SBIE 2019)

Rodrigues, A.P. C. (2018) Fio Condutor Pedagógico Metacognitivo: uma Máquina de Estados não Determinística para Elaboração de Games Inteligentes. Dissertação de Mestrado- PPGI - Universidade Federal do Rio de Janeiro.

Seminério, Franco Lo Presti, et al. (1997) O imaginário cognitivo: uma fronteira entre consciência e inconsciente. Arq. bras. psicol. Rio J. 1979, v.49, n.4, p.94-107.

Wing, J. M. Computational Thinking. (2006) Communications of the ACM. March, Vol. 49, No. 13, 2006 